\title{
Pembuatan Magnetometer ber-tranduser Efek Hall
}

\author{
Bachtera Indarto, ${ }^{*}$ Melania Suweni Muntini, dan Darminto \\ Jurusan Fisika-FMIPA, Institut Teknologi Sepuluh Nopember \\ Kampus ITS Sukolilo, Surabaya 61111
}

\begin{abstract}
Intisari
Telah dibuat sebuah magnetometer untuk menentukan karakteristik magnetik bahan magnet dan bahan superkonduktor. Magnetometer yang dibuat terdiri dari pembangkit intensitas medan magnet $\mathrm{H}$ dan pengukur induksi medan magnet $\mathrm{B}$. Pembangkit intensitas medan magnet $\mathrm{H}$ untuk pengukuran bahan magnet berupa solenoida berinti besi dan untuk bahan super konduktor berupa solenoida inti udara. Sumber arus mampu memberi arus untuk pembangkit magnet sebesar 54.000 Amp/m. Pengukur induksi untuk bahan magnet menggunakan transduser efek Hall A-1302 dengan kemampuan ukur maksimum (1800 \pm 1$)$ Gauss dan untuk superkonduktor menggunakan sensor elemen Hall dengan kemampuan ukur maksimum $(22,7 \pm 0,1)$ Gauss. Hasil pengukuran untuk 3 jenis bahan magnet adalah,(a). pasir besi mempunyai nilai saturasi (200 \pm 1 ) Gauss, remanensi $(30 \pm 1)$ Gauss dan koersivitas $(1.800 \pm 1) \mathrm{Amp} / \mathrm{m}$,(b). serbuk mash mempunyai nilai saturasi $(30 \pm 1)$ Gauss, remanensi $(20 \pm 1)$ Gauss dan koersivitas $(1.800 \pm 1) \mathrm{Amp} / \mathrm{m},(\mathrm{c})$. serbuk tab mash mempunyai nilai saturasi $(40 \pm 1)$ Gauss, remanensi $(25 \pm 1)$ Gauss dan koersivitas $(1.800 \pm 1) \mathrm{Amp} / \mathrm{m}$. Pengukuran $\mathrm{T}_{c}$ untuk 2 bahan superkonduktor Bi-2212 dan (Bi,Pb) 2212 adalah $(85 \pm 1) \mathrm{K}$ dan $(79 \pm 1) \mathrm{K}$.
\end{abstract}

KATA KUNCI: magnetometer, efek Hall, $\mathrm{T}_{c}$

\section{PENDAHULUAN}

Magnetometer adalah alat untuk menentukan karakeristik suatu bahan magnet. Pada dasarnya terdiri dari pembangkit intensitas medan magnet $\mathrm{H}$ dan pengukur besar induksi medan magnet $\mathrm{B}$ yang timbul akibat interaksi bahan dengan medan magnet $\mathrm{H}$ serta perangkat pengatur, pengolah dan penampil data [1].

Magnetometer terdiri dari 2 jenis yaitu scalar magnetometer yang hanya mengukur kuat medan magnet dan vector magnetometer yang dapat mengukur medan magnet pada arah tertentu. Beberapa jenis magnetometer yang termasuk scalar magnetometer adalah rotating coil magnetometer, Hall effect magnetometer dan proton precession magnetometer. Sedangkan yang termasuk jenis vector magnetometer adalah fluxgate magnetometer, SQUID (superconducting quantum interference devices) magnetometer dan SERF (spin exchange relaxation free) atomic magnetometer. Magnetometer dari tipe vektor umumnya jauh lebih peka dari pada tipe scalar [2].

Pembangkit intensitas medan magnet $\mathrm{H}$ yang umum digunakan adalah sebuah solenoida yang dialiri arus [3]. Arus tersebut diperoleh dari sebuah sumber arus yang mempunyai sifat dapat memberikan arus secara tetap tanpa dipengaruhi oleh hambatan solenoida [4]. Besar dan pola intensitas medan magnet $\mathrm{H}$ diatur komputer dengan cara mengatur pola dan besar aliran arus. Perangkat lunak pada komputer memberikan data digital yang dikonversi menjadi data analog oleh DAC (Digital to Analog Converter) untuk masukan sumber arus [5].

Pengukur besar induksi medan magnet B menggunakan sebuah transduser efek Hall [6]. Keluaran transduser berorde $\mathrm{mV}$ perlu diperkuat menggunakan penguat instrumentasi [7].

\footnotetext{
*E-MAIL: indarto@physics.its.ac.id
}

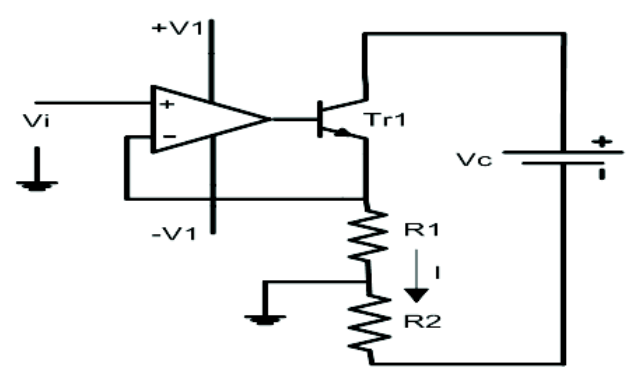

Gambar 1: Konfigurasi op-amp dan transistor sebagai sumber arus [8]

Keluaran penguat instrumentasi yang berupa besaran analog diubah mejadi besaran digital oleh ADC (Analog to Digital Converter) untuk diolah komputer [5].

Perangkat lunak komputer mengolah data intensitas medan magnet $\mathrm{H}$ dan induksi medan magnet $\mathrm{B}$ menjadi kurva karakteristik B - H yang memberikan karakteristik bahan uji [1].

\section{TINJAUAN PUSTAKA}

\section{A. Pembangkit Intensitas Medan Magnet $\mathbf{H}$}

Sumber arus adalah alat yang dapat memberikan arus tanpa terpengaruh oleh besarnya beban yang dipasang [8]. Sebuah sumber arus dapat dibuat dengan konfigurasi op-amp dan transistor dengan beban ditanahkan seperti Gambar 1. Kedua masukan op-amp terhubung singkat semu, sehingga kedua masukan mempunyai tegangan yang sama. Akibatnya tegangan pada $\mathrm{R}_{1}$ sama dengan $\mathrm{V}_{i}$, sehingga arus yang mengalir di $\mathrm{R}_{1}$ 


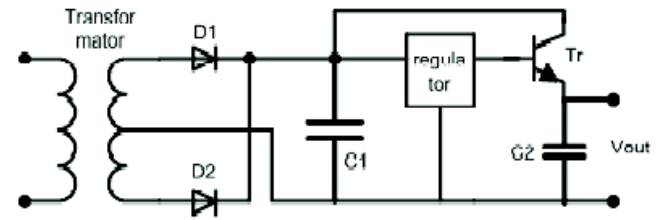

Gambar 2: Rangkaian catu daya teregulasi

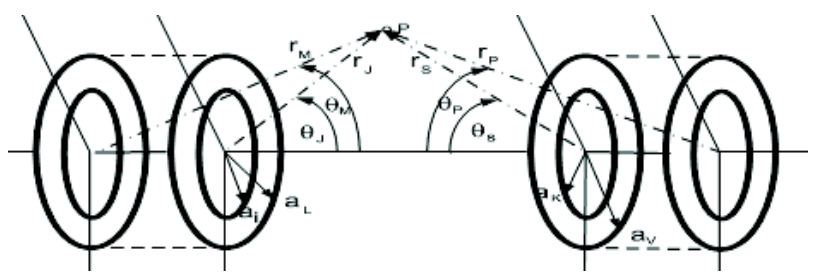

Gambar 3: Solenoida pembangkit medan magnet $\mathrm{H}$

adalah :

$$
I=\frac{V_{i}}{R_{1}}
$$

Arus I tersebut juga mengalir di $\mathrm{R}_{2}$ yang merupakan beban. Variasi arus pada beban I dapat diperoleh dengan memberikan $\mathrm{V}_{i}$ yang bervariasi. Arus maksimum yang mengalir dapat dihitung dengan cara sebagai berikut, persamaan tegangan di rangkaian $\operatorname{Tr}_{1}$ adalah:

$$
V_{c}=I R_{1}+I R_{2}+V_{c e}
$$

dengan $\mathrm{V}_{c e}$ : tegangan kolektor - emitor $\operatorname{Tr}_{1}$. Keadaan maksimum dipenuhi oleh $\mathrm{V}_{c e}=0$, berarti $V_{c}=I R_{1}+I R_{2}$ dan

$$
I_{m a k s}=\left(\frac{V_{c}}{R_{1}+R_{2}}\right)
$$

yang berarti ada suatu nilai $R_{1}$ maksimum untuk setiap nilai arus dan beban yang ditetapkan. Catudaya $\mathrm{V}_{c}$ pada Gambar 1, diperoleh dari sebuah rangkaian catu daya yang teregulasi seperti Gambar 2.

Pada Gambar 2 tegangan jala-jala sebesar $220 \mathrm{~V}_{a c}$ diturunkan oleh transformator penurun tegangan menjadi CT$15 \mathrm{~V}_{a c}$ yang kemudian disearahkan oleh rangkaian dioda penyearah gelombang penuh dan diratakan oleh kapasitor dan menjadi tegangan searah dengan faktor konversi dari $a c$ ke $d c$ sekitar 1,4. Sebuah regulator dipasang untuk mendapatkan nilai tegangan yang konstan sedangkan rangkaian transistor penyangga berfungsi memberikan arus yang lebih besar.

Pembangkit intensitas magnet yang sering digunakan adalah solenoida yaitu kawat lingkaran ditumpuk sehingga berbentuk silinder seperti Gambar 3 [1]. Besar medan magnet sepanjang sumbu kedua solenoida adalah:

$$
\begin{aligned}
\vec{B}(z)= & \left.\Sigma_{J=1}^{M}\left[\Sigma_{i=1}^{N}\left(\frac{\mu_{\circ} \ell a_{i}^{2}}{2\left(a_{i}^{2}+r_{j}^{2}\right)}\right)^{3 / 2}\right) \hat{r_{j}}\right]+ \\
& \left.\Sigma_{S=1}^{P}\left[\Sigma_{K=1}^{V}\left(\frac{\mu_{\circ} \ell a_{k}^{2}}{2\left(a_{K}^{2}+r_{s}^{2}\right)}\right)^{3 / 2}\right) \hat{r_{s}}\right]
\end{aligned}
$$

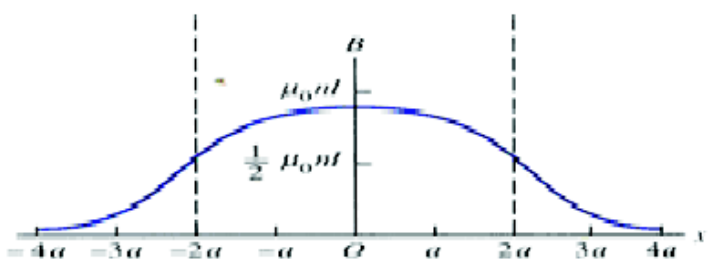

Gambar 4: Pola distribusi induksi medan magnet dalam solenoid

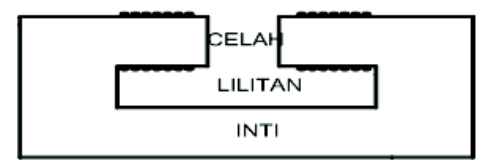

Gambar 5: Solenoida dengan inti bercelah

sedangkan besar medan magnet $\mathrm{H}$ di titik tengah kedua solenoida adalah

$$
\vec{B}(z)=2 \Sigma_{J=1}^{M}\left[\Sigma_{i=1}^{N}\left(\frac{\mu_{\circ} \ell a_{i}^{2}}{2\left(a_{i}^{2}+r_{j}^{2}\right)^{3 / 2}}\right) \hat{r}_{j}\right]
$$

Distribusi induksi medan magnet B untuk solenoida dengan jari-jari a dan panjang solenoida $\mathrm{L}=4$ a seperti pada Gambar 4. Induksi maksimum di bagian tengah solenoida, yaitu pada jarak 2a dari tepi solenoida dan besarnya mendekati $\mathrm{nI}=\mathrm{NI} / \mathrm{L}$.

Secara praktis penggunaan solenoida yang diberi inti akan menyulitkan pengamat dalam melakukan pengamatan sampel, karena tidak mungkin menempatkan sampel ditengah solenioda. Untuk itu, yang umum dilakukan adalah penempatan inti didalam lilitan dengan konfigurasi seperti Gambar 5.

Medan magnet $\mathrm{H}$ pada celah sepanjang sumbu inti pada Gambar 5 mempunyai nilai serba sama, semakin rapat celah semakin luas pula daerah dengan medan $\mathrm{H}$ yang homogen.Penambahan inti pada solenoida menyebabkan induksi medan magnet B tidak lagi berasal dari solenoida saja, tapi ada penambahan induksi medan magnet karena magnetisasi pada inti. Sehingga induksi medan magnet total adalah :

$$
B_{t}=B_{\text {sol }}+B_{i n}
$$

dengan $\mathrm{B}_{\text {sol }}$ adalah induksi medan magnet oleh solenoida dan $\mathrm{B}_{\text {in }}$ induksi medan magnet karena magnetisasi inti.

\section{B. Pengukur Induksi Medan magnet B}

Efek Hall adalah fenomena terdefleksinya aliran muatan pada keping logam yang diletakkan dalam medan magnet. Defleksi aliran muatan menyebabkan timbulnya beda potensial diantara sisi keping yang disebut potensial Hall seperti pada Gambar 6. Efek Hall pada keping logam timbul karena adanya interaksi muatan (elektron) yang bergerak dengan medan magnet. Muatan tersebut mendapatkan gaya Lorenzt $\mathrm{F}=\mathrm{q}(\mathrm{v} \times \mathrm{B})$ yang menyebabkan muatan terdefleksi pada 


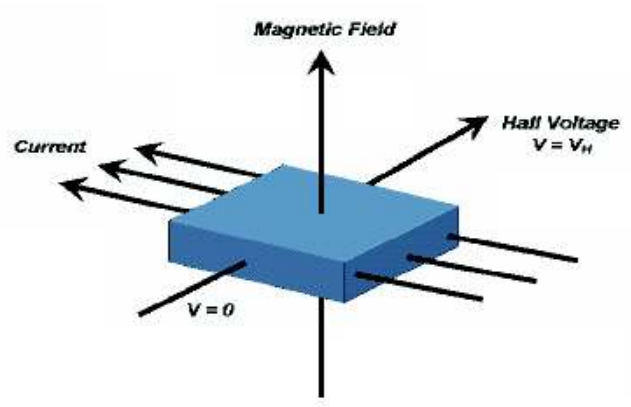

Gambar 6: Fenomena Hall pada keping logam yang dikenai medan magnet

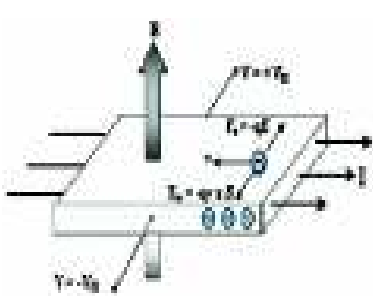

(a) (b)

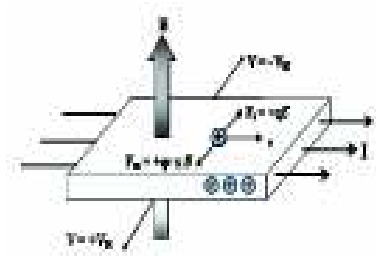

Gambar 7: Elemen Hall semikonduktor tipe $\mathrm{n}$ dan $\mathrm{p}$ dalam medan magnet

arah tegak lurus terhadap arah kecepatan muatan dan arah medan magnet. Dengan demikian timbulnya potensial pada sisi keping yang sejajar dengan arah arus.

Elemen Hall adalah keping bahan semikonduktor yang digunakan untuk mengkonversi medan magnet ke tegangan berdasarkan fenomena efek Hall. Ada 2 jenis bahan semikonduktor yang digunakan yaitu tipe $\mathrm{n}$ (muatan mayoritasnya elektron) dan $\mathrm{p}$ (muatan mayoritasnya lubang), masing masing tipe berinteraksi dengan medan magnet seperti yang pada Gambar 7.

Pada Gambar 7, arah aliran arus searah sumbu x positif dan medan magnet searah sumbu z positif. Untuk semikonduktor tipe $n$, elektron yang bergerak kearah sumbu x negatif (berlawanan arah dengan aliran I) dipengaruhi gaya Lorentz sehingga garis arusnya bergeser kearah sumbu y negatif. Bergesernya garis arus (elektron) pada sumbu y negatif menyebabkan timbulnya medan listrik yang berlawanan arah dengan gaya Lorentz. Kondisi tersebut menyebabkan sisi sumbu y negatif berpolaritas negatif dan sisi sumbu y positif berpolaritas positif. Pada semikonduktor tipe $p$, bergesernya garis arus (lubang) karena pengaruh gaya Lorentz sama seperti halnya tipe $n$, karena muatannya positif dan arah kecepatannya searah sumbu x positif (searah aliran I), gaya listrik yang timbul menyebabkan polaritas sisi sumbu y negatif menjadi positif dan sisi sumbu y positif menjadi negatif.

Sensor Hall dibuat dari elemen Hall dan penguat bising rendah penguatan tinggi dikemas menjadi satu rangkaian terintegrasi seperti yang ditampilkan Gambar 8. Keluaran elemen Hall dihubungkan dengan penguat diferensial sehingga kelu-

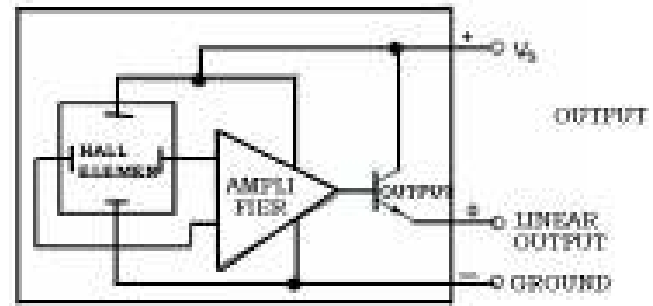

Gambar 8: Rangkaian dalam sensor efek Hall

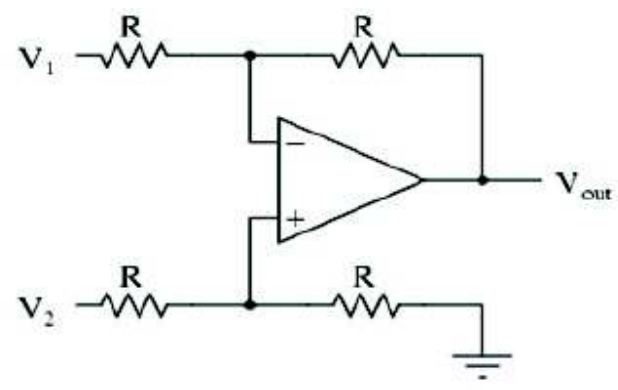

Gambar 9: Penguat diferensial penggeser tegangan keluaran sensor efek Hall

aran sensor sebanding dengan $\mathrm{V}_{\text {Hall }}$. Regulator ditambahkan agar keluaran sensor selalu stabil. Keluaran sensor mempunyai nilai $\frac{1}{2}$ dari catu daya, sehingga titik tegangan acuan saat tanpa medan magnet, tidak pada 0 volt tetapi $\frac{1}{2}$ tegangan catu. Titik acuan $\frac{1}{2}$ tegangan catu disebut sebagai tegangan kuisien (quiesenct voltage). Sifat yang lain adalah adanya saturasi pada tegangan keluaran saat diterapkan medan magnet yang melebihi batas kemampuan.

Sensor efek Hall mempunyai titik acuan $\frac{1}{2}$ tegangan catudaya. Titik acuan dapat digeser pada 0 volt dengan cara menghubungkan keluaran sensor pada penguat diferensial seperti Gambar 9. Jika nilai semua hambatan dibuat sama maka tegangan keluarannya memenuhi persamaan:

$$
V_{\text {out }}=V_{1}-V_{2}
$$

Bila masukan $\mathrm{V}_{2}$ dihubungkan dengan keluaran sensor efek Hall pada Gambar 8 dan masukan $\mathrm{V}_{1}$ dihubungkan dengan tegangan referensi yang besarnya sama dengan tegangan keluaran sensor efek Hall tanpa medan, maka keluaran rangkaian Gambar 10 berada pada 0 volt.

\section{Sistem Pengamatan}

Pengamatan bahan dilakukan dengan menempatkan suatu wadah sampel pada daerah dengan medan magnet yang homogen seperti pada Gambar 10. Daerah medan magnet yang homogen adalah pada celah antara inti disekitar sumbu inti, diusahakan sampel diletakkan pada celah diantara inti pembangkit medan magnet. Besar induksi medan magnet total:

$$
B_{t}=B_{\text {sol }}+B_{\text {in }}+B_{\text {sam }}
$$




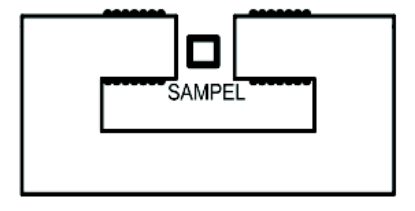

Gambar 10: Sistem untuk pengamatan bahan

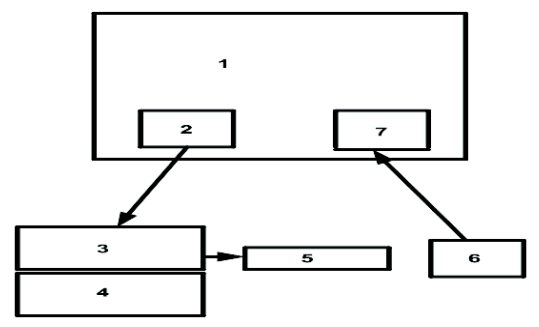

Gambar 11: Blok Diagram Perangkat Keras.

dengan $\mathrm{B}_{\text {sol }}$ : induksi medan magnet solenoida, $\mathrm{B}_{\text {in }}$ : induksi medan magnet inti dan $\mathrm{B}_{\text {sam }}$ : induksi medan magnet sampel.

\section{Komputer Sebagai Pengatur dan Pengolah Data}

Perangkat lunak komputer mengatur intensitas medan magnet $\mathrm{H}$ melalui pengaturan keluaran sumber arus. Data digital yang bersesuaian dengan nilai intensitas magnet diubah oleh DAC menjadi data analog. Data analog keluaran DAC menjadi masukan dari sumber arus. Besaran yang perlu diketahui pada DAC adalah waktu ayun (setting time), yaitu waktu terjadinya perubahan sinyal masukan digital hingga konverter mencapai nilai $\frac{1}{2}$ LSB dari nilai analognya.

Besaran yang diukur adalah tegangan keluaran sensor efek Hall . Keluaran berupa tegangan analog. Agar bisa dibaca oleh komputer besaran tersebut harus diubah menjadi besaran digital oleh alat yang disebut sebagai konverter analog ke digital atau ADC. Parameter yang perlu diketahui pada proses konversi adalah kesalahan kuantisasi, ketidaklinearan, kode tidak lengkap dan waktu konversi.

\section{METODOLOGI}

\section{A. Blok Diagram magnetometer}

Magnetometer yang dibuat merupakan gabungan dari perangkat keras dan perangkat lunak. Perangkat kerasnya melibatkan rangkaian elektronika dan peralatan mekanik. Diagram blok rancangan magnetometer yang akan dibuat seperti Gambar 11.

Gambar 11 merupakan rancangan magnetometer yang terdiri dari (sesuai dengan nomor) adalah komputer, DAC, sumber arus, catu daya, lilitan, transduser efek Hall, penguat instrumentasi dan ADC. Selain merupakan rancangan juga

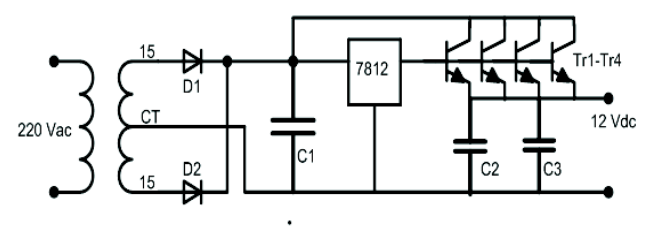

Gambar 12: Rangkaian catudaya teregulasi 12 volt $10 \mathrm{Amp}$

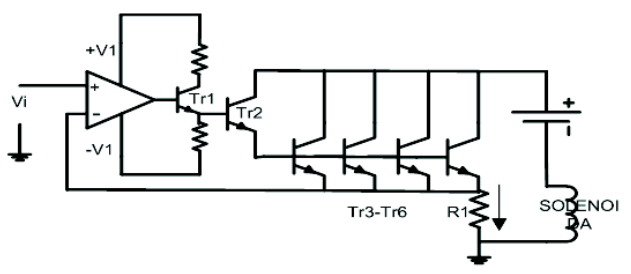

Gambar 13: Rangkaian sumber arus tinggi

menggambarkan hubungan masing masing blok yang dikoordinasi oleh komputer.

\section{B. Pembangkit Intensitas Medan Magnet $\mathbf{H}$}

Catu daya sebagai sumber daya yang digunakan untuk rangkaian sumber arus harus teregulasi agar fluktuasi pada jala-jala tidak mempengaruhi aliran arus pada solenoida. Rancangan catu daya yang dimaksud adalah seperti Gambar 12 .

Transformator $\mathrm{T}_{1}$ menurunkan tegangan dari $220 \mathrm{~V}_{a c}$ menjadi CT - $15 \mathrm{~V}_{a c}$ kemudian disearahkan oleh dioda $\mathrm{D}_{1}$ dan $\mathrm{D}_{2}$ yang diratakan oleh kapasitor $\mathrm{C}_{1}$ menjadi tegangan dc sebesar $\mathrm{V}_{d c}=1,4 \times 15$ volt $=19$ volt. Regulator 7812 memberikan keluaran 12 volt yang teregulasi. $\operatorname{Tr}_{1}-\operatorname{Tr}_{4}$ berfungsi sebagai penyangga ketika rangkaian ditarik arus $10 \mathrm{Amp}, \mathrm{C}_{2}$ dan $\mathrm{C}_{3}$ berfungsi penyaring agar bising mengalir ke tanah.

Intensitas medan magnet $\mathrm{H}$ yang dibangkitkan diinginkan dalam bentuk sapuan, sehingga arus yang akan dialirkan ke solenoida juga mempunyai bentuk sapuan. Aliran arus berbentuk sapuan dapat diperoleh apabila masukan dari sumber arus juga berbentuk sapuan. Rancangan rangkaian sumber arus yang akan dibuat adalah seperti Gambar 13. Bila dirancang untuk arus $10 \mathrm{Amp}$ dan $\mathrm{V}_{i}=5$ volt, sesuai Pers. (1), hambatan $\mathrm{R}_{1}$ adalah $=\frac{5}{10} \mathrm{Ohm}=0,5 \mathrm{Ohm}$. Untuk $\mathrm{V}_{c}=12$ volt, hambatan maksimum beban ( solenoida ) sesuai Pers. (3) yaitu :

$$
\begin{aligned}
I_{\text {maks }} & =\frac{V_{c}}{R 1+R 2} \\
R_{2} & =\frac{V_{c}-I R_{1}}{I}=\frac{12-100,5}{10}=0,7 \Omega
\end{aligned}
$$

Nilai $\mathrm{R}_{2}$ ( solenoida ) menjadi acuan untuk jumlah lilitan maksimum yang bisa dibuat.

Intensitas medan magnet $\mathrm{H}$ untuk pengukuran mensyaratkan distribusi yang homogen pada daerah tertentu. Pada solenoida inti udara, distribusi nilai intensitas medan magnet 


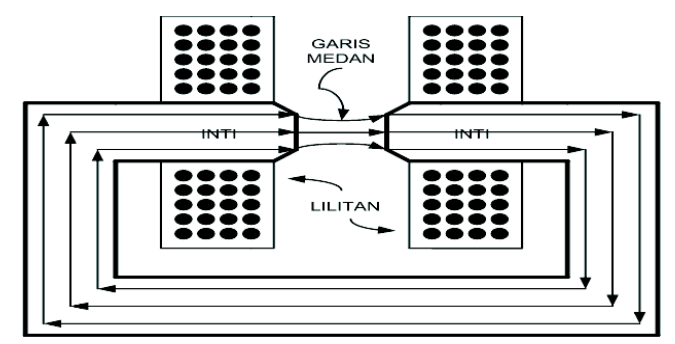

Gambar 14: Konfigurasi pembangkit medan magnet homogen

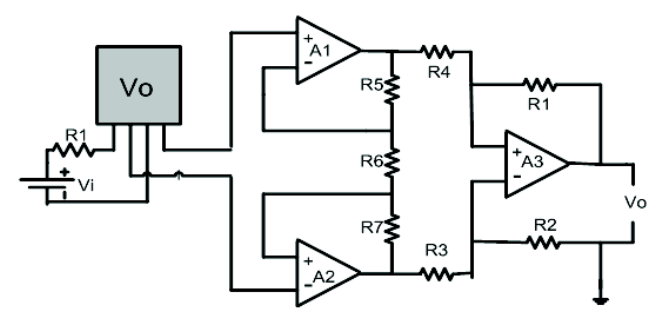

Gambar 15: Rangkaian pengukur induksi medan magnet B

$\mathrm{H}$ disetiap titik tidak homogen. Untuk itu bentuk rancangan pembangkit medan intensitas magnet $\mathrm{H}$ seperti Gambar 14.

Pada Gambar 14, ujung inti pada celah dibuat membentuk sudut dengan ujung tumpul, sehingga pola garis medan seperti pada gambar tersebut. Pembangkit dirancang dengan jumlah lilitan sebanyak 600 lilitan, panjang solenoida $0,04 \mathrm{~m}$ dan arus 5 Amp. Intensitas magnet inti udara adalah $\mathrm{H}=(600 \times 5) /$ $0,04 \mathrm{Amp} / \mathrm{m}=75.000 \mathrm{Amp} / \mathrm{m}$. Bila 2 lilitan digabung akan diperoleh $\mathrm{H}=150.000 \mathrm{Amp} / \mathrm{m}$ dan $\mathrm{B}=1884$ Gauss. Adanya inti pada solenoida menyebabkan besar induksi medan magnet bertambah, sehingga induksi total $\mathrm{B}=\mathrm{B}_{\text {sol }}+\mathrm{B}_{\text {in }}$. Besarnya induksi total dapat ditentukan melalui kalibrasi dan karakterisasi solenoida beserta intinya sebagai satu kesatuan.

\section{Pengukur Induksi Medan magnet B}

Pengukur induksi terdiri transduser efek Hall dan penguat instrumentasi dengan konfigurasi seperti Gambar 3.5 Nilai $\mathrm{R}_{1}$ yang berfungsi sebagai pembatas arus transduser efek Hall pada Gambar 15 sebesar 3,3 KOhm untuk $\mathrm{V}_{i}=5$ volt sesuai dengan rangkaian pemutar disket. Nilai resistor pada penguat instrumentasi yaitu $\mathrm{R}_{1}=\mathrm{R}_{2}=1 \mathrm{MOhm}, \mathrm{R}_{5}=\mathrm{R}_{6}=\mathrm{R}_{7}=100$ Kohm, $\mathrm{R}_{3}$ dan $\mathrm{R}_{4}$ menggunakan resistor variabel. Op-amp yang digunakan adalah LF-356. Sesuai dengan Pers. 6 faktor penguatan tergantung pada perbandingan $\mathrm{R}_{6}$ dan $\mathrm{R}_{4}$, dengan demikian faktor penguatan pada Gambar 15 untuk bagian penguat instrumentasi hanya pada nilai $\mathrm{R}_{4}$ karena nilai $\mathrm{R}_{6}$ dibuat tetap. Keluaran $\mathrm{V}_{\circ}$ diatur sebesar 5 volt untuk nilai induksi maksimum disesuaikan dengan maksimum masukan ADC.

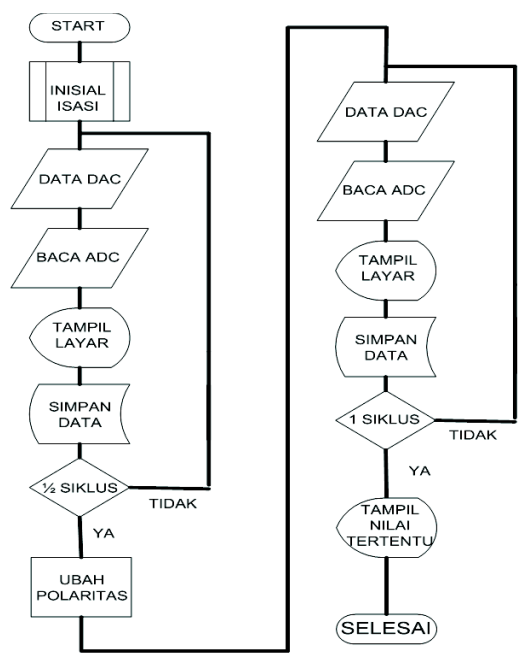

Gambar 16: Diagram alir perangkat lunak pengamatan bahan

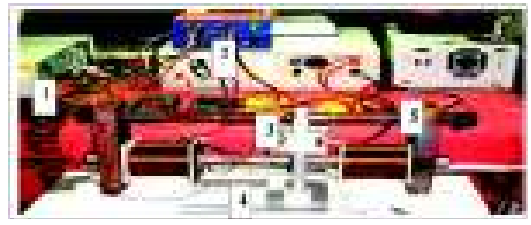

Gambar 17: Magnetometer bahan magnetik

\section{Perangkat Lunak}

Koordinasi pengamatan bahan pada temperatur ruang dengan pola intensitas medan magnet $\mathrm{H}$ : 0 - maksimum 0 minimum - 0 sesuai dengan diagram alir seperti Gambar 15. Diagram alir pada Gambar 15 menunjukkan proses pengamatan bahan dengan sapuan 1 siklus. Pada $\frac{1}{2}$ siklus awal sapuan dilakukan medan magnet dari 0 sampai maksimum dan dari maksimum ke 0. Setiap nilai medan yang diberikan dan medan yang diukur transduser ditampilkan sebagai pasangan titik pada kurva B-H. Kemudian aliran arus dirubah dengan membalikkan polaritas lilitan sehingga arah medan berbalik arah. Proses $\frac{1}{2}$ siklus diulang sehingga sapuan lengkap 1 siklus. Pada akhir proses, data direkam dalam format Excel.

\section{PERAKITAN MAGNETOMETER DAN ANALISIS DATA PENGUKURAN}

Perakitan alat berdasarkan rancangan magnetometer yang ditunjukkan Gambar 11. Setiap bagian yang telah dirakit, dikarakterisasi dan dikalibrasi dan setelah digabung dilakukan kalibrasi ulang. Hasil rakitan seperti yang ditunjukkan Gambar 17. Magnetometer untuk bahan magnetik pada Gambar 17 terdiri dari DAC dan ADC yang dirakit dalam CPU, pengkondisi sinyal, sumber arus, pembangkit magnet dan , wadah sampel, catudaya. 


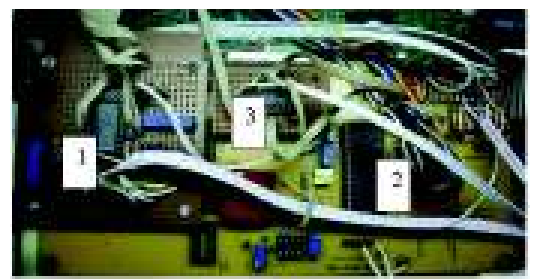

Gambar 18: Rangkaian DAC dan ADC

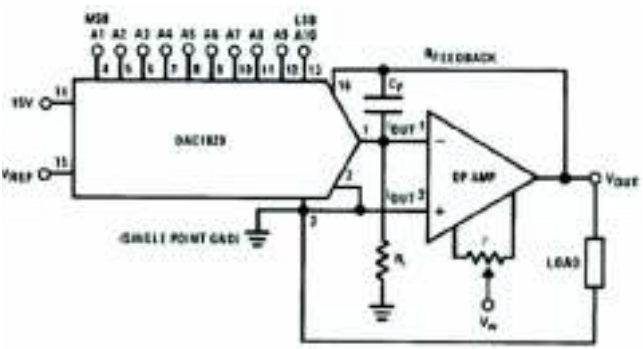

Gambar 19: Rangkaian konverter sinyal digital ke analog DAC1220(Burr-Brown)

\section{A. Pengatur dan Dengolah Data}

Hasil rakitan rangkaian konversi sinyal digital ke analog (DAC) dan konversi sinyal analog ke digital (ADC) ditempatkan dalam CPU seperti pada Gambar 18. Nomor 1 adalah bagian rangkaian DAC, nomor 2 adalah rangkaian $\mathrm{ADC}$ dan nomor 3 adalah rangkaian selektor 8 masukan 1 keluaran.

Rangkaian DAC menggunakan komponen utama DAC1220 yang mengkonversi sinyal digital 12 bit menjadi analog. Rangkaian yang dirakit seperti Gambar 19, dengan jalur data sebanyak 12 dihubungkan ke komputer melalui PPI 8255. Agar keluaran dari DAC cukup stabil maka untuk tegangan referensi diperoleh dari keluaran rangkaian Gambar 20, dan tegangan referensi didapat dari keluaran penyangga op-amp yang mendapat masukan dari sebuah dioda zener 2,5 volt.

Karakterisasi dilakukan dengan cara memberi data pada DAC kemudian diukur tegangan keluarannya. Hasil pengukuran menunjukkan rata-rata setiap data memberikan nilai tegangan setiap bit seperti grafik Gambar 21, bit terkecil memberikan keluaran sebesar 1,25 mV, dengan kata lain keluaran DAC 12 bit, minimum 0 volt dan maksimum $4096 * 1,25 \mathrm{mV}$

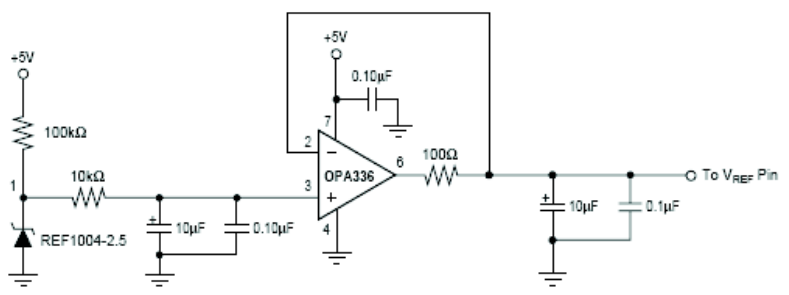

Gambar 20: Rangkaian pemberi tegangan referensi untuk DAC (Burr-Brown)

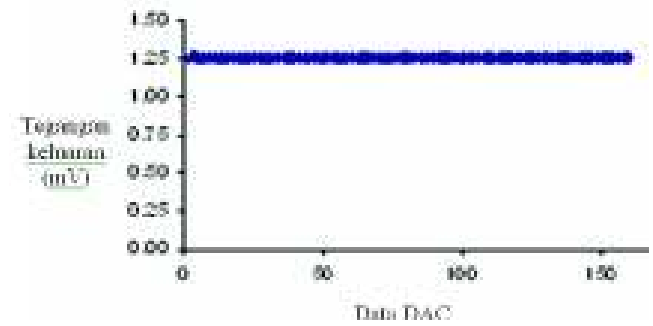

Gambar 21: Grafik tegangan setiap bit untuk data DAC

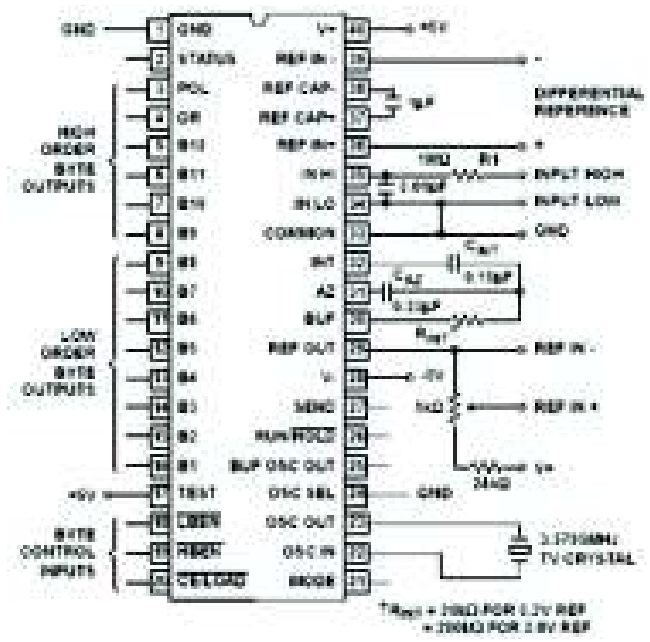

Gambar 22: Konverter sinyal analog ke digital 12 bit ICL-7109 (Intersil)

\section{$=5120 \mathrm{mV}$.}

Rangkaian ADC menggunakan ICL-7109 (Intersil) sebagai komponen utama yang mengkonversi sinyal analog menjadi data 12 bit digital. Rangkaian yang dibuat seperti Gambar 22, jalur keluaran hasil konversi sinyal analog dihubungkan ke komputer melalui PPI 8255. Karakterisasi dan kalibrasi untuk ADC terlebih dahulu adalah menentukan daerah kerja yang mungkin, yaitu dengan menghubungkan keluaran DAC dengan masukan ADC, hasilnya seperti pada Gambar 23.

DAC yang digunakan adalah 12 bit sehingga jumlah data yang mampu dikeluarkan adalah sebanyak 4096 data. Tampak pada Gambar 23, masukan yang dikonversi oleh ADC tidak

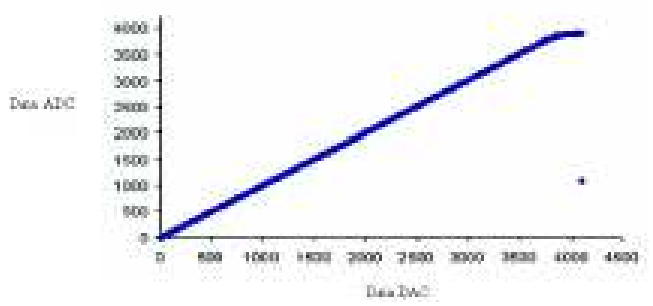

Gambar 23: Grafik masukan ADC terhadap keluaran DAC 


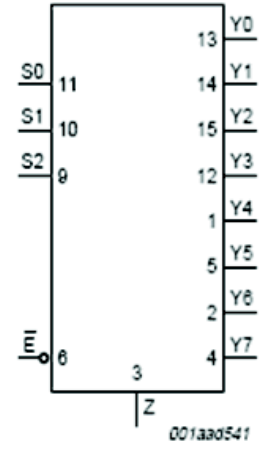

Gambar 24: Selektor 8 masukan 1 keluaran 74HCT4051(Philips data sheet)

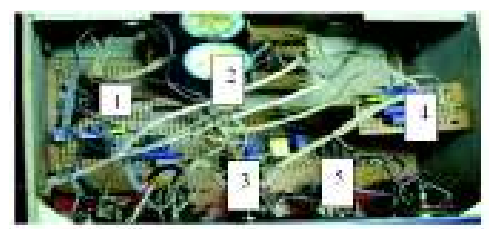

Gambar 25: Rangkaian rangkaian pengkondisi sinyal

sampai 4096. Dari data yang diperoleh, daerah kerja linier ADC mulai dari 0 sampai 3800. Sedangkan besar tegangan terkecil yang dapat di konversi oleh ADC sama dengan keluaran DAC yaitu $1,25 \mathrm{mV}$.

Selektor masukan 8 masukan ke satu keluaran menggunakan 74HCT4051 seperti pada rangkaian Gambar 24, 8 masukan yang hubungan dengan keluaran diatur oleh kombinasi $\mathrm{S}_{0}, \mathrm{~S}_{1}$ dan $\mathrm{S}_{3}$. Keluaran rangkaian dihubungkan dengan rangkaian ADC Gambar 22. Adanya tambahan rangkaian selektor, ADC dapat mengkonversi 8 masukan sinyal analog secara bergantian sehingga ADC dapat membaca 8 masukan yang berbeda secara bergantian.

\section{B. Pengkondisi Sinyal Pengukur Medan Magnet}

Sensor pada umumnya mempunyai keluaran yang relatif kecil, bahkan beberapa tidak bersifat linier dalam mengkonversi besaran fisis menjadi besaran listrik. Ketika dikondisikan, besar sinyal harus disesuaikan dengan rangkaian berikutnya. Apabila besaran besaran tersebut hendak diolah oleh komputer, maka besar sinyal disesuaikan dengan ADC yang digunakan. Pengkondisi sinyal yang diperlukan oleh ADC-7109 adalah yang memberi keluaran sebesar 5 volt. Untuk mempermudah pengoperasian, rangkaian pengkondisi sinyal dirakit dalam satu boks. Rangkaian pengkodisi sinyal pada Gambar 25 adalah untuk pengukur sifat magnetik bahan dan sifat magnetik bahan superkonduktor.

Pengukur induksi medan magnet terdiri dari sensor efek Hall dan rangkaian penggeser titik acuan seperti Gambar 26. Sensor efek Hall mempunyai 3 pin, pin 1 untuk catu daya

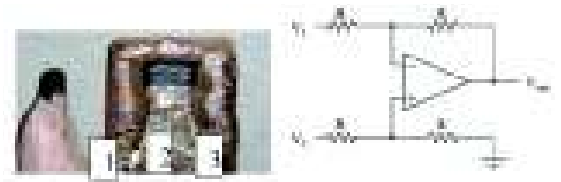

Gambar 26: Pengukur sifat magnetik bahan

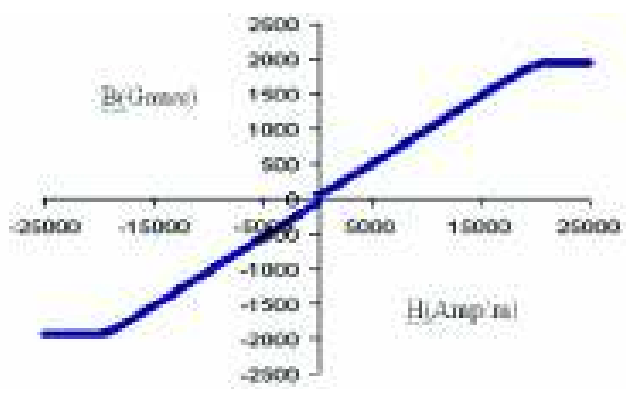

Gambar 27: Keluaran pengukur medan magnet

5 volt, pin 2 untuk tanah dan pin 3 merupakan keluaran sensor. Pengukuran tanpa medan magnet, keluaran sensor sebesar 2,56 volt. Agar keluaran sensor tanpa medan magnet sebesar 0 volt, pin 3 dihubungkan dengan masukan $V_{2}$ dari rangkaian penggeser titik acuan, sedangkan masukan $\mathrm{V}_{1}$ diberi sumber tegangan variabel dari -5 volt sampai +5 volt. Tegangan diatur sehingga keluaran rangkaian penggeser sebesar 0 volt. Penguatan rangkaian diatur sebesar 1,25/1,3 sehingga keluaran pengukur adalah 1,25 mV/Gauss sesuai tegangan terkecil yang dapat dikonversi oleh ADC.

Pemberian medan magnet bervariasi pada pengukur menghasilkan variasi keluaran pada rangkaian pengukur yang dirakit (Gambar 27). Keluaran pengukur mulai mencapai saturasi yaitu keluaran maksimum sebesar 1900 Gauss, pada penerapan medan sekitar $20000 \mathrm{Amp} / \mathrm{m}$. Daerah pengukuran diatas 1800 Gauss, hasilnya mulai tidak linier, sehingga batas ukur maksimum pengukur yang digunakan adalah 1800 Gauss.

\section{Pembangkit Magnet, Sumber Arus, Pemegang Sensor/Sampel}

Selain pengukur besar medan magnet, bagian dari magnetometer adalah pembangkit magnet yang terdiri dari sumber arus dan solenoida. Perakitan sumber arus sesuai rancangan pada Gambar 19 yang terdiri dari beberapa bagian yaitu konverter tegangan ke arus, penguat arus dan hambatan referensi. Hasil perakitan sumber arus ditunjukkan Gambar 28, nomor 1 adalah konverter tegangan ke arus yang menerima masukan dari DAC, nomor 2 adalah penguat arus yang terdiri dari 6 buah transistor daya dengan kemampuan masing-masing 10 Amp dan nomor 3 adalah hambatan referensi sebesar 0,22 Ohm yang menjaga aliran arus selalu tetap. Mengingat arus yang ditarik oleh solenoida cukup besar, transistor daya dan hambatan referensi perlu diberi pendingin. 


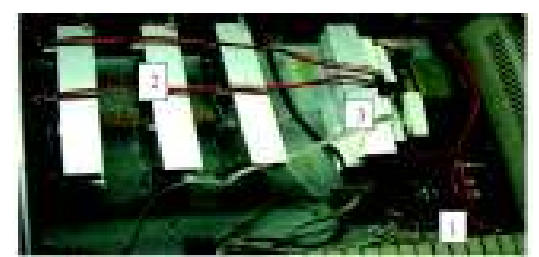

Gambar 28: Rangkaian sumber arus

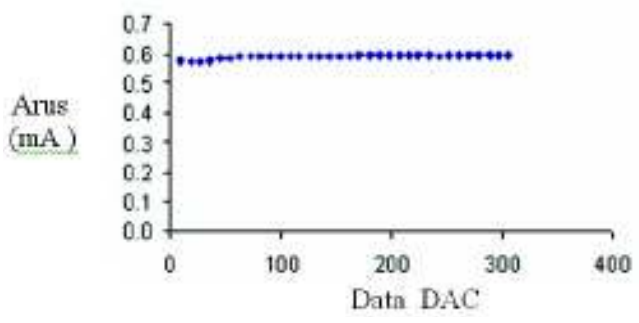

Gambar 29: Grafik keluaran sumber arus terhadap setiap bit data DAC

Karakterisasi dan kalibrasi dilakukan dengan cara memberi data pada DAC kemudian arus yang mengalir diamati menggunakan amperemeter digital pada batas ukur maksimum 200 mA. Hasil pengujian ditunjukan Gambar 29, yang diperoleh dengan cara memberi data bervariasi pada DAC kemudian setiap data dicari arus terkecil, dari grafik tersebut diperoleh bahwa arus terkecil yang dapat diatur oleh DAC adalah 0,6 $\mathrm{mA}$.

Uji coba sumber arus dilakukan dengan memberikan data dari DAC dari 0 sampai 3800 dengan perubahan 4 bit. Aliran arus dibaca oleh ADC dan hasilnya seperti yang ditampilkan dalam bentuk grafik pada Gambar 30, dengan aliran arus maksimum sebesar 12644,3 mA untuk data DAC sebesar 3800 . Dengan demikian sumber arus yang dirakit mempunyai spesifikasi arus paling kecil adalah 3,3 mA/bit data DAC.

Pembangkit magnet yang dirakit terdiri dari 2 solenoida, pengatur posisi sampel dan pemegang sensor/sampel. Konfigurasi rakitan seperti Gambar 31, 2 solenoida masing masing 450 lilitan dengan panjang $10 \mathrm{~cm}$, inti solenoida dari besi dan pemegang sensor/sampel. Untuk 2 solenida tersebut faktor pengali kuat medan magnet yang dibangkitkan (n/l) adalah $4500 / \mathrm{m}$. Pemegang sensor dan wadah sampel seperti pada Gambar 32, nomor 1 adalah sensor Hall, ditempatkan agar

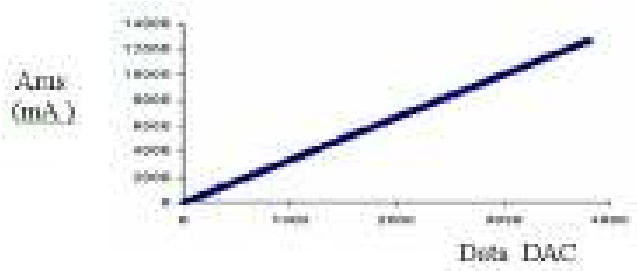

Gambar 30: Grafik aliran arus dari sumber arus terhadap data $\operatorname{DAC}(0-3800)$

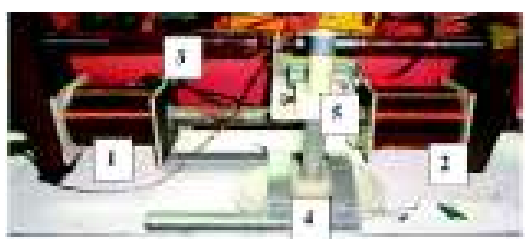

Gambar 31: Pembangkit Magnet

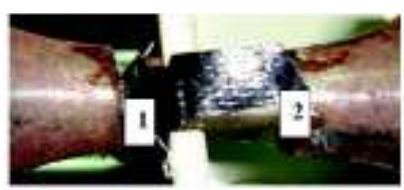

Gambar 32: Pemegang sensor dan wadah sampel

posisinya tepat ditengah inti dan rapat dengan wadah sampel, yaitu nomor 2.

Karakterisasi dan kalibrasi dilakukan untuk beberapa intensitas magnetik 45.000 Amp/m, 29.700 Amp/m dan 15.750 Amp/m. Hasil pengukuran ditampilkan dalam bentuk grafik seperti yang ditunjukkan Gambar 33. Tampak pada Gambar 33,walaupun ada remanensi tapi sistem pembangkit belum mencapai saturasi. Karakteristik pembangkit tidak akan mengganggu pengukuran bahan magnetik selama saturasi bahan tersebut masih dibawah intensitas magnet maksimum pembangkit magnet.

\section{Pengukuran dan Pengolahan Data}

Proses pengukuran karakteristik sampel adalah memberi sapuan medan $\mathrm{H}$ dan mengukur medan induksi B. Sapuan

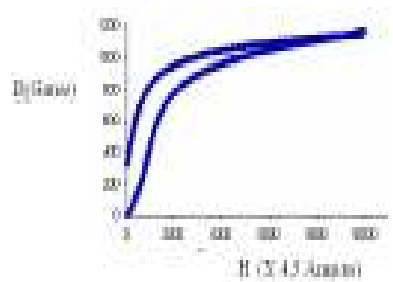

(a)

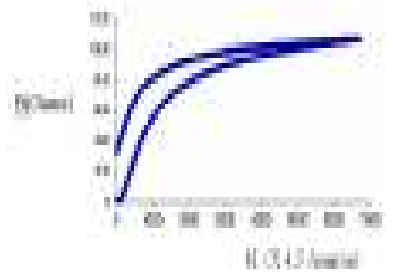

(b)

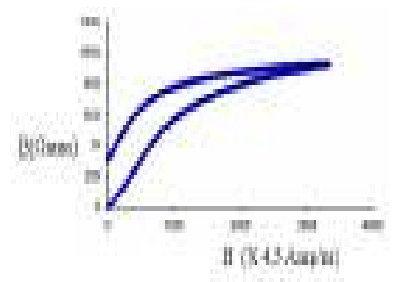

(c)

Gambar 33: Grafik karakteristik pembangkit magnet dengan kuat medan (a). $\mathrm{H}=45.000 \mathrm{Amp} / \mathrm{m}$, (b). $\mathrm{H}=29.700 \mathrm{Amp} / \mathrm{m}$,(c). $\mathrm{H}$ $=15.750 \mathrm{Amp} / \mathrm{m}$ 


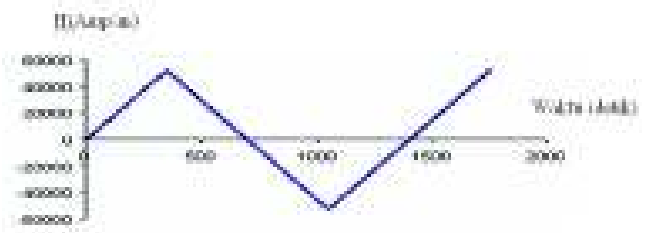

Gambar 34: Pola sapuan medan magnet

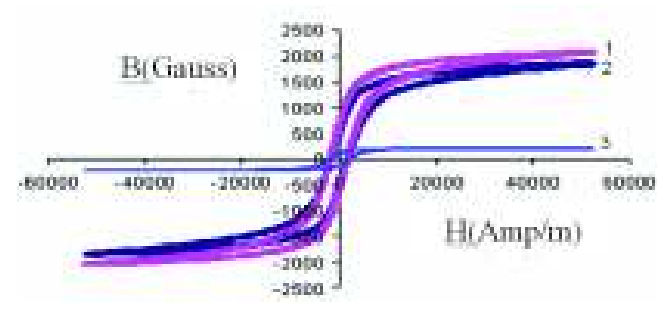

Gambar 35: Grafik hasil uji pasir besi dengan medan uji 54.000 $\mathrm{Amp} / \mathrm{m}$.

medan $\mathrm{H}$ diperoleh dari sapuan aliran arus pada solenoida. Pemberian sapuan medan untuk pengukuran sampel berbentuk segitiga yang berupa berupa fungsi arus terhadap waktu. seperti Gambar 34. Medan magnet maksimum dan waktu sapuan pada Gambar 34 dapat diatur melalui komputer. Besar medan maksimum disesuaikan dengan karakteristik sampel, sedangkan waktu sapuan dapat diatur dengan memberi delay. Waktu sapuan paling minimum sama dengan besarnya waktu konversi dari ADC.

Pengukuran karakteristik bahan magnetik meliputi beberapa langkah yaitu pengukuran tanpa sampel, pengukuran sampel dan pengolahan data yang direkam menggunakan pengolah data.. Pengolahan data berdasarkan persamaan yang secara operasional prosesnya adalah luas grafik pengukuran dengan sampel dikurangi luas grafik tanpa sampel dan hasilnya adalah grafik karakteristik sampel. Bahan yang diuji sebanyak 3 macam, yaitu pasir besi, serbuk mash dan serbuk tab mash. Sampel pasir besi yang diuji adalah pasir besi yang telah diproses tahap pertama dalam pembuatan nano partikel. Penggunaan medan uji maksimum dimaksudkan untuk mengetahui secara kasar, besar medan saat sampel mencapai saturasi. Gambar 35 menampilkan 3 macam grafik, yaitu (1). grafik pengukuran dengan sampel, (2). grafik pengukuran tanpa sampel, (3). grafik karakteristik dari sampel dengan keadaan saturasi tercapai pada arus pembangkit medan antara 2.000 Amp/m sampai $4000 \mathrm{Amp} / \mathrm{m}$.

Untuk mendapatkan grafik yang lebih teliti grafik karakteristik sampel ditampilkan tersendiri seperti Gambar 36. Sampel sudah mencapai saturasi antara $10.000 \mathrm{Amp} / \mathrm{m}$ sampai 15.000 Amp/m, yang berarti medan yang diterapkan terlalu besar. Informasi mulai terjadinya saturasi menjadi acuan besarnya medan yang harus diberikan untuk pengukuran yang lebih teliti. Berdasar grafik pada Gambar 36, pengukuran dilakukan dengan medan $12.000 \mathrm{Amp} / \mathrm{m}$, hasilnya seperti yang ditunjukkan Gambar 37.

Sama halnya dengan Gambar 35 sebelumya, Gambar 37

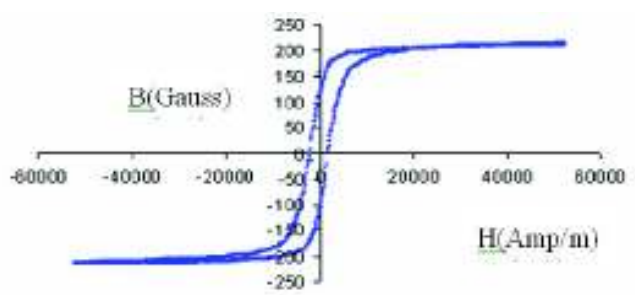

Gambar 36: Karakteristik pasir besi dengan medan uji 54000 Amp/m

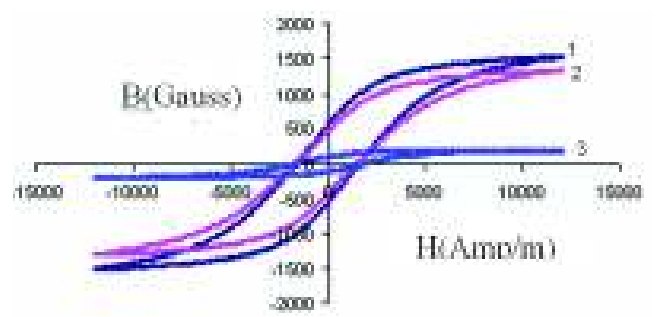

Gambar 37: Grafik hasil uji pasir besi dengan medan uji 12.000 $\mathrm{Amp} / \mathrm{m}$

menampilkan grafik hasil pengukuran, (1). pengukuran dengan sampel, (2). pengukuran tanpa sampel,(3). grafik karakteristik sampel. Grafik karakteristik sampel tampak seperti yang ditampilkan pada Gambar 38, saturasi sampel tercapai disekitar 200 Gauss, remanensi di 100 Gauss dan medan koersif sebesar $1.800 \mathrm{Amp} / \mathrm{m}$.

Pengujian bahan magnetik yang lain adalah serbuk mash, bahan tersebut diuji dengan medan magnet maksimum sebesar $30.000 \mathrm{Amp} / \mathrm{m}$. Hasil pengujian seperti grafik pada Gambar 39, (1). pengukuran dengan sampel, (2). pengukuran tanpa sampel, (3). grafik karakteristik sampel. Grafik karakteristik sampel tampak seperti yang ditampilkan pada Gambar 40, dengan saturasi tercapai pada medan sebesar 30 Gauss, remanensi sampel sebesar 20 Gauss dan koersifnya pada medan yang dibangkitkan oleh arus $1.800 \mathrm{Amp} / \mathrm{m}$.

Sampel serbuk tablet mash diuji dengan medan magnet uji maksimum sebesar $30.000 \mathrm{Amp} / \mathrm{m}$.Hasil pengujian tampak pada Gambar 41,(1). pengukuran dengan sampel, (2). pengukuran tanpa sampel, (3). grafik karakteristik sampel. Bila grafik karakteristik sampel ditampilkan tersendiri, hasilnya adalah seperti pada Gambar 42, dan saturasi tercapai pada

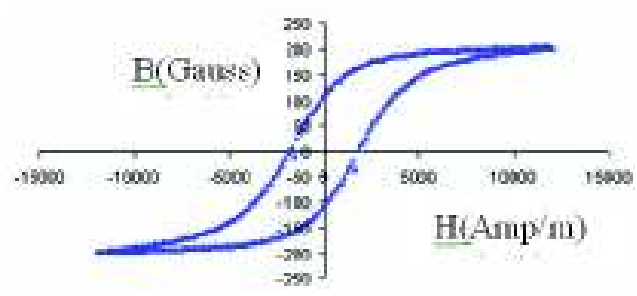

Gambar 38: Grafik karakterisitik pasir besi dengan medan uji 12.000 $\mathrm{Amp} / \mathrm{m}$ 


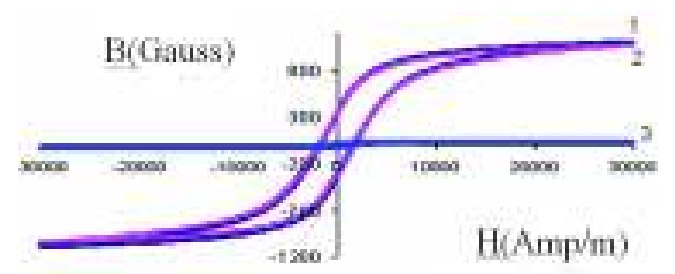

Gambar 39: Grafik hasil uji bahan serbuk mash dengan medan uji $30.000 \mathrm{Amp} / \mathrm{m}$

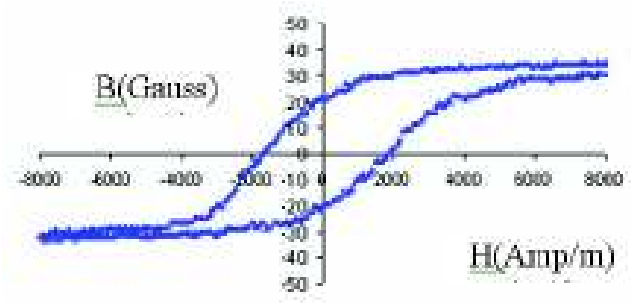

Gambar 40: Karakteristik serbuk mash dengan arus uji 30.000 $\mathrm{Amp} / \mathrm{m}$

medan sebesar 40 Gauss, remanensi sampel sebesar 25 Gauss dan koersifnya pada medan yang besarnya $1800 \mathrm{Amp} / \mathrm{m}$.

Pengukuran ketiga jenis sampel memberi hasil yang berbeda, ditinjau dari jenis bahan, ketiganya termasuk bahan magnetik lunak karena saturasi dicapai dalam orde ratusan Gauss. Ditinjau dari luasan grafik yang meggambarkan besarnya medan magnet untuk memagnetisasi, pasir besi lebih besar dan paling kecil serbuk mash. Hal tersebut berkaitan dengan ukuran domain dari masing masing bahan. Bahan serbuk mash dan serbuk tablet mash mempunyai ukuran nano. Semakin besar domain semakin besar pula medan magnet yang diperlukan untuk memagnetisasi semakin besar pula luas grafik karakteristiknya.

\section{SIMPULAN}

Magnetometer pengukur karakteristik bahan magnet yang dibuat mempunyai pembangkit intensitas magnet dengan ke- mampuan memberi kuat medan maksimum 54.000 Amp/m dan pengukur medan magnet maksimum $(1800 \pm 1)$ Gauss.

Magnetometer pengukur karakteristik magnetik superkon-

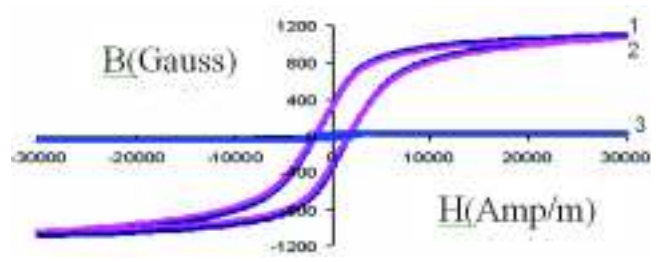

Gambar 41: Grafik hasil uji serbuk tablet mash dengan medan uji $30.000 \mathrm{Amp} / \mathrm{m}$

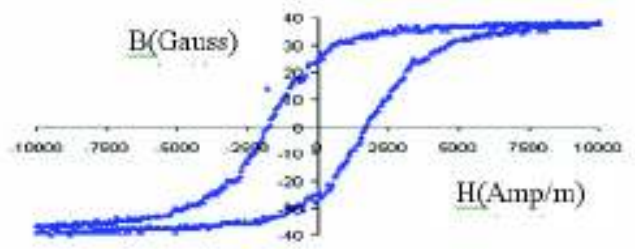

Gambar 42: Karakteristik serbuk tablet mash dengan medan uji $30.000 \mathrm{Amp} / \mathrm{m}$

duktor yang dibuat mempunyai pembangkit intensitas magnet dengan kemampuan memberi kuat medan maksimum 3.400 $\mathrm{Amp} / \mathrm{m}$ dan pengukur medan magnet maksimum $(22,7 \pm 1)$ Gauss.

Pengukuran yang dilakukan untuk 3 jenis bahan magnet hasilnya adalah : Pasir besi mempunyai nilai saturasi (200 $\pm 1)$ Gauss, remanensi $(30 \pm 1)$ Gauss dan koersivitas (1.800 $\pm 1) \mathrm{Amp} / \mathrm{m}$. Serbuk mash mempunyai nilai saturasi $(30 \pm 1)$ Gauss, remanensi $(20 \pm 1)$ Gauss dan koersivitas $(1.800 \pm 1)$ Amp/m. Serbuk tab mash mempunyai nilai saturasi $(40 \pm 1)$ Gauss, remanensi $(25 \pm 1)$ Gauss dan koersivitas (1.800 \pm 1$)$ $\mathrm{Amp} / \mathrm{m}$.
[1] Cullity B.D., Introduction to Magnetic Material (AddisonWesley Publishing Company, Indiana, 1972).

[2] www.wikipedia.com

[3] Paul A Tipler, alih bahasa Dr. Bambang Soegiono, Fisika Untuk Sains dan Teknik (Erlangga, Jakarta, 2004).

[4] Yahya E, Indarto B, Perencanaan dan Pembuatan Sumber Arus untuk Furnace Bebas medan Magnet Berubah yang Dapat Dikendalikan dengan Komputer, Lemlit ITS, Surabaya, 1996.

[5] Verlag, Franzis, alih bahasa Margunadi, Pengukuran, Pengendalian dan Pengaturan dengan PC (Elex Media Komputindo, Jakarta, 1990).

[6] Fraden Y, Hand Book of Modern Sensors, Physics Designs \&
Applications (Springer, New York, 2003).

[7] Indarto B, Rohedi, A. Y. , Automatisasi Pengukuran Arus Kritis Jc Bahan Super Konduktor, Lemlit ITS , Surabaya, 1995.

[8] Sutrisno, Elektronika Lanjutan, Teori Dasar dan Penerapannya (FMIPA-ITB, Bandung, 1994).

[9] Coughlin F., Robert and Frederick F. Driscoll, Penguat Operasional dan Rangkaian Terpadu Linier (Penerbit Erlangga, Jakarta, 1998).

[10] Honeywell,xxxx, Hall Effect Sensing and Application (MICRO SWITCH Sensing and Control, USA) 